anti-T. gondii IgG in oral fluid. It was then applied to 150 children aged $0-15$ months (341 samples) born from 133 women who seroconverted during pregnancy and 17 who remained seronegative. IgG on oral fluid were compared to serum IgG detected with MEIA AxSYM ${ }^{\circledR}$ Toxo IgG (Abbott Laboratories).

Results The pilot study validated the acceptability and the safety of the test and the adequate duration of sampling. IgG detected in serum and in oral fluid had a parallel kinetics among newborns (correlation coefficient: $0.59, \mathrm{p}<0.0001$ ), with a concordant decline in the non-infected ones $(\mathrm{n}=110)$, and matching raising or stable IgG in those who were congenitally-infected $(n=23)$.

Conclusions Collection of oral fluid is painless and inexpensive. Our new test provides a simple and rapid method to detect antiToxoplasma gondii IgG and to manage newborn at risk for congenital infection. It could have many other applications in pregnant women and other groups of patients.

\section{PO-0384 THE PRACTICAL METHOD TO DIAGNOSIS OF FOURTEEN CASES OF GLYCOGEN STORAGE DISEASES IN OUR LABORATORY}

L Yargui, N Gagi, M Djeddou, N Atia, S Gacem, A Berhoune. Medicine, CHU Mustapha Bacha, Algiers, Algeria

\subsection{6/archdischild-2014-307384.1030}

Glycogen storage diseases (GSD) are a group of inherited disorders of metabolism that result in storage of excess glycogen. Several well defined defects in one of the enzymes involved in the synthesis or degradation of glycogen have been described. There are over 15 types and they are classified based on the enzyme deficiency and the affected tissue (liver, muscle or both).

In this study, we wish to report the biochemical investigations adopted in main infantile GSD diagnosed in our laboratory.

Four steps diagnostic procedure have been assumed, taking into account several frequent clinical observations leading to further targeted biochemical parameters:

1. Assessment of the metabolic disorders with standard tests (fast blood glucose, uric acid, triglycerides, total cholesterol, ASAT, ALAT, CK, lactic acid).

2. Quantitative determination of glycogen in leucocytes (or erythrocytes) after extraction, precipitation and treatment with an throne reagent.

3. Oral galactose test with blood lactate and glucose estimations, in combination with a glucagon tolerance test to screen the main types of liver glycogenosis.

4. Lysosomal acid a-glucosidase activity when GSD type II (Pompe disease) is suspected.

Since 1995 and on the basis of this screening procedure and clinical features, 14 cases of GSD have been categorised:

- 6 forbes's disease (GSD III, debranching-enzyme deficiency)

- 3 von Gierke's disease (GSD I, glucose-6-phosphatase deficiency)

- 2 pompe's disease (GSD II, maltase acid deficiency)

- 1 Andersen's disease (GSD IV, branching-enzyme deficiency)

- 1 Hers's disease (GSD VI, hepatic phosphorylase deficiency)

- 1 GSD IX (phosphorylase kinase deficiency)

Our laboratory diagnostic approach include simple screening tests easy to implement in clinical chemistry laboratories. Thus, Pompe disease diagnosis is easily done in our laboratory. The measurement of tissue enzyme activities (liver and muscle) of the other enzymes is limited to some specialised laboratories. The molecular diagnosis offers a good alternative for GSD type 0, I and III but requires better financial means.
P0-385 WITHDRAWN

\section{Miscellaneous}

\section{P0-0385a ADVERSE CHILDHOOD EXPERIENCES IN ALBERTA, CANADA: A POPULATION BASED STUDY}

${ }^{1} \mathrm{~S}$ McDonald, ${ }^{2} \mathrm{D}$ Kingston, ${ }^{1} \mathrm{~S}$ Tough. ${ }^{1}$ Pediatrics, University of Calgary, Calgary, Canada; ${ }^{2}$ Nursing, University of Alberta, Edmonton, Canada

\subsection{6/archdischild-2014-307384.1031}

Objective Adverse childhood experiences (ACEs) are associated with poor health outcomes in adulthood. We developed ACE risk profiles using a domain-specific approach and examined ACEs as risk factors for diagnosed physical and mental health conditions.

Method A computer-assisted telephone survey was conducted with a random sample of adults in Alberta, Canada. Eight questions were asked on adversity during childhood, based on the original ACE survey and modified to reflect the Canadian context and research methodology. Descriptive and multivariable analyses were conducted.

Results Among the 1207 respondents, the majority were married or living common-law (65.8\%), had completed post-secondary education (78.2\%), and were Caucasian $(86.2 \%)$ with a mean age of 52.4 years $(\mathrm{SD}=16.3)$. Approximately one-third $(27.3 \%)$ experienced at least one type of abuse, and almost half (49.5\%) experienced at least one form of household dysfunction. ACEs were highly interrelated. Sixty-three percent fell into the low risk profile, with the remaining $37 \%$ divided among the three higher risk profiles. Overall, ACE risk profile was significantly associated with diagnosed mental health condition/addiction and chronic pain, controlling for sociodemographic characteristics.

Conclusion The ACE risk profile of ACEs in both the abuse domain and the household dysfunction domain conferred the greatest risk for poor health outcomes in adulthood. Given the interrelated of ACEs, a more comprehensive approach to conceptualization of ACEs is warranted. Results have implications for prevention of ACEs and recovery from ACEs to decrease disease burden. Strategies may include effective programs to prevent exposure to toxic stress and support nurturing and stable relationships for children and families.

\section{Neonatal Brain and Development}

\section{PO-0386 NEONATAL SEIZURES ON AEEG MONITORING AFTER IN UTERO EXPOSURE TO VENLAFAXINE}

${ }^{1}$ A Ansary, ${ }^{2}$ SE Ibhanesebhor, ${ }^{2} \mathrm{CM}$ Manjunatha. 'Paediatrics, Royal Alexandra Hospital, Paisley, UK; ${ }^{2}$ Neonatology, Wishaw General Hospital, Wishaw, UK

\subsection{6/archdischild-2014-307384.1032}

We report an unusual presentation of withdrawal from venlafaxine in a preterm baby of 29 weeks gestation, who presented with myoclonic seizures on second day of life. The seizures were confirmed with amplitude integrated EEG (aEEG). Other causes of neonatal seizures were excluded. She responded to treatment with phenobarbitone and phenytoin. Her MRI scan of the brain was normal and remains well on follow up. We believe this case to be the first report of seizure in a preterm baby resulting from maternal venlafaxine use and details the contribution of aEEG in the care of one such infant. 


\begin{tabular}{|c|c|c|c|}
\hline Criteria measured & Audit results & TOBY Trial & TOBY Register \\
\hline A criteria met & $95.6 \%$ & $100 \%$ * & \\
\hline B criteria met & $86.7 \%$ & $100 \%$ * & \\
\hline C criteria met & $75 \%$ & $100 \%$ * & \\
\hline Consultant documented as being involved in cooling decision & $77.8 \%$ ** & & \\
\hline Cooled by $6 \mathrm{~h}$ & $97.8 \%$ & $100 \%$ * & $81 \%$ \\
\hline \multirow[t]{4}{*}{$\%$ of cooled time in target range $\left(33-35^{*}\right)$} & $86.03 \%$ & & \\
\hline & Total - in $15.6 \%$ & & \\
\hline & - Seizures during rewarming $-8.9 \%$ & & \\
\hline & - Bradycardia $-4.4 \%$ & Total not available: & Total not available: \\
\hline Adverse events & - Subcutaneous fat necrosis $-2.2 \%$ & - Bradycardia - $5 \%$ & - Subcutaneous fat necrosis - $1 \%$ \\
\hline Survival to discharge & $84.4 \%$ & $74.2 \%$ & $67 \% * * *$ \\
\hline
\end{tabular}

(I should declare that I have presented this poster in an educational meeting in India. As it has come out nicely, I wish to present the poster again to European audience. I should also declare that information in this case has been used for a case report which has been accepted for publication in a journal. Thank you).

\section{PO-0387 IS IT COOL TO COOL IN A LOCAL (LEVEL 2) NEONATAL UNIT?}

${ }^{1}$ A Baines, ${ }^{2} \mathrm{M}$ Quinn, ${ }^{1} \mathrm{PF}$ Munyard. 'Paediatric Department, Royal Cornwall Hospital Trust, Truro, UK; ${ }^{2}$ Neonatal Department, Royal Devon and Exeter Hospital, Exeter, UK

\subsection{6/archdischild-2014-307384.1033}

Background and aims Hypoxic Ischaemic Encephalopathy (HIE) is associated with high levels of mortality and disability. A multicenter randomised control trial (TOBY Study), showed therapeutic hypothermia $(\mathrm{TH})$ increased survival without adverse neurological outcome, with only minor adverse events. The study was conducted in Level 2 (local) and Level 3 (intensive care) Neonatal units (NNUs), the majority of TH is now carried out in Level 3 NNUs, which is reflected in national guidance. Exeter and Truro local NNUs cooled 45 infants over a 34-month period. Results are presented.

Methods Retrospective audit of 45 infants who underwent $\mathrm{TH}$ for HIE in two local NNUs (Exeter $\mathrm{n}=28$, Truro $\mathrm{n}=17$ ). Cooling practices were audited against TOBY Trial criteria and NICE guidance for the first time.

Results

Conclusions We suggest TH can be carried out effectively and safely in Local NNUs with appropriate training and expertise.

\begin{tabular}{|c|c|c|c|c|c|}
\hline & & Rate (\%) & $p$-value & Relative Risk & Cl95\% \\
\hline & ROP-Laser & 25 & $\mathrm{NS}^{*}$ & 1.46 & $0.43-4.95$ \\
\hline & ROP-NT & 16.7 & & 0.97 & $0.10-9.84$ \\
\hline \multirow[t]{3}{*}{ Refractive errors } & MROP & 17.1 & & 1 & \\
\hline & ROP-Laser & 0 & $\mathrm{NS}^{*}$ & NA & \\
\hline & ROP-NT & 28.6 & & 2.34 & $0.56-9.80$ \\
\hline \multirow[t]{3}{*}{ Visual acuity $(<0.8)$} & MROP & 12.2 & & 1 & \\
\hline & ROP-Laser & 30 & NSt & 1.02 & $0.35-3.01$ \\
\hline & ROP-NT & 28.6 & & 0.97 & $0.27-3.50$ \\
\hline Visual outcome & MROP & 29.4 & & 1 & \\
\hline
\end{tabular}

${ }^{*}$ Chi-square, tMantel-Haenszel Test for Trend.

\section{PO-0388 LONG TERM FOLLOW UP OF A COHORT OF PRETERM INFANTS DIAGNOSED OF RETINOPATHY OF PREMATURITY}

${ }^{1} \mathrm{C}$ Balcells, ${ }^{1} \mathrm{~T}$ Agut, ${ }^{1} \mathrm{C}$ Moreno, ${ }^{2} \mathrm{~A}$ Serra, ${ }^{2} \mathrm{M}$ Morales, ${ }^{1} \mathrm{M}$ Iriondo. ${ }^{1} \mathrm{Centre}$ de Medicina Maternofetal I Neonatal Barcelona, Sant Joan de Déu I Hospital Clínic, Barcelona, Spain; ${ }^{2}$ Ophtalmology, Sant Joan de Déu, Barcelona, Spain

\subsection{6/archdischild-2014-307384.1034}

Background and aims Retinopathy of prematurity (ROP) is still a worldwide leading cause of childhood blindness. We aimed to describe the visual outcome at 5 years in a cohort of preterms diagnosed of ROP.

Method We analysed the data based of preterm infants $\leq 32$ weeks and/or $\leq 1500 \mathrm{~g}$ born between January2002 and December2008 with the diagnosis of ROP who were followed up. Visual outcome was evaluated at 5 years using visual acuity (impaired $<0.8$ ), strabismus and refractive errors (myopia <-3D or hypermetropia $>3 \mathrm{D}$ ).

Results 71 patients were followed-up (mean age 27weeks and mean weight 951g). 64.8\% had moderate ROP (MROP), 15,5\% not treated severe ROP (ROP-NT) and 19,7\% severe ROP treated with laser (ROP-Laser). At the age of 5 years, $21.1 \%$ weared glasses, $14,1 \%$ had the diagnosis of refractive errors (1 myopia and 9 hypermetropia). Only one patient, with moderate ROP had strabismus. We did not find differences in the visual prognosis according to the severity of ROP. (Table1)

Conclusions In our cohort, patients with severe ROP (treated or not) do not have a worse visual prognosis at five years than those with moderate ROP. These findings are probably related to the gestational age of the study population.

\section{PO-0389 OUTCOME OF VERY PRETERM CHILDREN AT SCHOOL AGE: RESULTS FROM THE AREA-BASED ITALIAN ACTION FOLLOW-UP STUDY}

${ }^{1} \mathrm{M}$ Cuttini, ${ }^{1} \mathrm{M}$ Lacchei, ${ }^{1} \mathrm{G}$ Riccio, ${ }^{1} \mathrm{C}$ Giorno, ${ }^{1} \mathrm{C}$ Rosa, ${ }^{2} \mathrm{C}$ Melon, ${ }^{2} \mathrm{M}$ Carrozzi, ${ }^{3} \mathrm{P}$ Brovedani, ${ }^{4} \mathrm{~V}$ Chiandotto, ${ }^{4} \mathrm{E}$ Pessina, ${ }^{4} \mathrm{~N}$ Bressan, ${ }^{5} \mathrm{~V}$ Svelto, ${ }^{5} \mathrm{~F}$ Voller. ${ }^{1}$ Research Unit of Perinatal Epidemiology, Pediatric Hospital Bambino Gesu, Roma, Italy; ${ }^{2}$ Department of Neuroscience, Burlo Garofolo Hospital, Trieste, Italy; ${ }^{3}$ Neonatal Intensive Care Unit, Burlo Garofolo Hospital, Trieste, Italy; ${ }^{4}$ Neonatal Intensive Care Unit, S. Maria Della Misericordia Hospital, Udine, Italy; ${ }^{5}$ Osservatorio Di Epidemiologia, Agenzia Di Sanità Della Toscana, Firenze, Italy 